\title{
Parental experiences of feeding problems in their infants with Down syndrome
}

\author{
Eilene Lewis and Alta Kritzinger \\ Department of Communication Pathology, University of Pretoria, South Africa
}

\begin{abstract}
Although feeding difficulties in infants with Down syndrome are described in the literature, the experiences of parents regarding the feeding problems of their infants are largely omitted. In order to promote closer collaboration with families and speech-language therapists in early communication intervention, the study investigated some experiences of a group of parents concerning the feeding problems of their infants with Down syndrome. A descriptive survey approach was implemented to collect quantitative data. The results revealed the type of feeding problems and associated conditions occurring in the infants of the twenty participants; the type of feeding methods used; the assistance received during the feeding problems; the emotions experienced in relation to the feeding problems in their infants as well as suggestions made by the participants regarding the management of early feeding problems. Numerous feeding problems occurred in the infants and the variety of emotions experienced by the participants indicated that feeding therapy and counseling were required. As a result of the different conditions underlying the feeding problems of the participants' infants, a comprehensive approach, which included therapeutic and medical intervention, was necessary. In order to provide effective early communication intervention services from birth, the results indicated that the knowledge, skills and sensitivity of speech language therapists to identify caregiver needs, to provide appropriate family-focused intervention and to make recommendations regarding the management of feeding problems in infants with Down syndrome is of great importance.
\end{abstract}

Keywords: Down syndrome, feeding problems, early communication intervention, caregiver experiences, family-focused intervention

\section{Introduction}

While collaboration with caregivers is a goal but also a significant challenge in early intervention, the benefits of a family-focused approach cannot be underestimated (Bailey, 1996). Efforts to increase caregiver involvement in the early intervention process benefit the child and improve longterm expectations (Rossetti, 2001). Since family-focused services form the basis of effective early intervention service delivery (Guralnick, 1997), parental experiences with their young children and perceptions of these experiences provide valuable insights to improve services for families with infants with disabilities.

Parents have no choice and are usually the first persons who have to deal with the feeding difficulties of their infants with Down syndrome (Beck, 1999), yet descriptions of the firsthand experiences and perceptions of parents regarding the feeding problems in their infants are difficult to find in the literature. Conversely, the professional perspective of the typical feeding problems of infants with Down syndrome is widely described.

Little is known about the underlying causes of feeding problems in infants with Down syndrome. Some authors have suggested that they may be associated with low muscle tone, which also affects the strength, mobility and range of motion of the oral muscles (Kumin, Goodman \& Councill, 1991) and can result in weak sucking, swallowing, lip closure, and tongue protrusion (Pilcher, 1998; Kumin, 1994), and gastroesophageal reflux (McCurtin, 1997).

The combination of reduced oral space and limited control also contribute to feeding problems in infants with Down syndrome. Due to a small oral cavity and midfacial hypoplasia, the infant's lips appear thin, the palate is usually flatter with a high arch in the midline and the nasal passages are narrowed. The combination of reduced oral space and low muscle tone can result in tongue protrusion. True macroglossia can sometimes occur in infants with Down syndrome, which results in additional problems 
with breathing, chewing and speech development later on (Pilcher, 1998). Narrowed nasal passages and increased respiratory secretions interfere with nasal breathing and oral feeding in infants with Down syndrome (McCurtin, 1997). Cleft palate, secondary to the chromosomal anomaly of Down syndrome, only occurs in $0.5 \%$ of the infants (McWilliams, Morris \& Shelton, 1990), but significantly increases feeding problems.

The presence of heart defects in about $40 \%$ of infants with Down syndrome, is another important risk factor contributing to feeding problems as well as health, growth and development of the infants. Depending on the type and severity of the heart defect, excessive perspiration, fast and difficult breathing, vomiting, fatigue during feeding, inadequate food intake and limited weight gain can occur. As a result of increased pulmonary pressure in young infants with heart defects, the typical symptoms of the heart defect may be masked and parents can be unaware of the cause of their infant's feeding problem (Cousineau \& Lauer, 1995). Early identification of a heart defect in an infant is therefore most important for the accurate description and appropriate intervention of the complex feeding problems of infants with Down syndrome.

Lastly, the risk for intrauterine growth retardation resulting in low birth weight in infants with Down syndrome (Lubchenco, 1987) and the combination of low birth weight and its sequelae, as well as low muscle tone, can result in early feeding problems in infants with Down syndrome (Venter, Christianson, Hutamo, Makhura \& Gericke, 1995).

As a result of the early feeding problems in infants with Down syndrome, and the emotional responses of parents to the often unexpected diagnosis of Down syndrome (Cunningham, 1982), early mother-infant attachment may be disrupted and breast feeding is often not possible (Gigacz, 2001; Rynders \& Horrobin, 1996; Van Dyke, Mattheis, Eberly \& Williams, 1995). Feeding problems in infants with Down syndrome change as they grow older, but remain a challenge for parents and speech-language therapists. The infants may experience problems with transition from breast/bottle feeding to cup feeding, and from liquids to solids which can result in inadequate lip closure, poor chewing ability and choking (Pipes, 1995; Kumin, 1994).

Feeding therapy appears to be an important component of early intervention services to families with infants with Down syndrome, but challenges exist for speech-language therapists in the South African context. Great diversity in the backgrounds of young children who need early intervention and an insufficient number of speech-language therapists (Pickering, McAllister, Hagler, Whitehill, Penn, Robertson \& McCready, 1998) to serve the increased population of infants with Down syndrome (Venter, et al., 1995) result in insufficient services for parents with infants with Down syndrome. In order to contribute to early communication intervention services responsive to specific parental needs, the aim of the study is to investigate some of the feeding experiences of a group of parents with their infants with Down syndrome.

\section{Method}

\section{Aim}

The aim of the descriptive survey was to describe some of the experiences of a group of parents regarding the feeding problems of their infants with Down syndrome.

\section{Participants}

Addresses of parents with young children with Down syndrome were obtained from the Down Syndrome Association of Pretoria. A total of 27 parents with young children under the age of four agreed to participate in the study. Of the 27 questionnaires that were sent to parents, 20 were returned. The ages of the 20 participants' children varied between 12 and 48 months at the time of data collection and there were 9 boys and 11 girls. Eight infants had low birth weight $(<2500 \mathrm{~g})$ and the gestation period of 16 infants ranged from minor to moderate pre-term birth. Seventeen $(85 \%)$ of the participants' infants experienced low muscle tone and/or heart defects, one participant had duodenal atresia, one participant experienced decreased immunity, and one participant presented with infantile spasms.

\section{Material}

A questionnaire was designed and used as data collection instrument. In order to enhance the face validity and internal validity (Leedy, 1997) of the questionnaire a pilot study was conducted, utilizing one participant. The results indicated some changes, and in its final format the questionnaire consisted of 26 questions to elicit biographical information, data on conditions associated with Down syndrome in the infants, the feeding process and problems, support received, the participants' feelings about their infants' feeding problems and their recommendations for improved feeding intervention (See Appendix A).

\section{Results and Discussion}

\section{Feeding problems that occurred in the participants' infants}

A total of $75 \%$ of participants reported that the duration of the feeding process was between 30 and 60 minutes in the first three months of life. According to Wolf and Glass (1992) feeding duration exceeding more than 30 minutes indicates potential feeding problems. One of the infants required gastrostomy feeding and $40 \%$ infants were fed via nasogastric tube during the neonatal period. While the majority of the participants attempted breast feeding, only a third of the participants were successful in breast feeding their infants. This is an important result since breast feeding promotes mother-infant attachment, and optimal attachment can decrease maternal stress associated with the diagnosis of Down syndrome in an infant (Wolf \& Glass, 1992). 
Figure 1 displays the different feeding problems experienced by the participants' infants.

According to Figure 1 a large number of feeding problems were reported by the participants and most of these problems manifested during the period from birth to three months of age. Heart defects and low muscle tone present in $85 \%$ of the participants' infants can be associated with the most often occurring problem, exhaustion, that were reported in $80 \%$ of the infants (Pilcher, 1998; Cousneau \& Lauer, 1995; Kumin, 1994) (see Figure 1 no. 8). When arranged in chronological order according to the natural sequence of the feeding process, the interrelated nature of the 14 different feeding problems of the infants in Figure 1 became clear. For example, infants with low muscle tone are difficult to position correctly for feeding (see Figure 1 no. 6 ), since they require more support (Hunt, Lewis, Reisel, Waldrup \& Wooster, 2000). Decreased muscle tone is also associated with problems starting sucking (no. 12), a poor lip seal (no. 9), slow sucking and swallowing reflex (no. 10 and 11) and an uncoordinated suck/swallow/breathing pattern (uncoordinated SSB) (no. 5) (Wolf \& Glass, 1992). These conditions may contribute to coughing (no. 3), choking (no. 1), aspiration (no. 13), milk escaping through the nose (no. 4), and vomiting (no. 2) which can result in cramps (no. 7) and exhaustion before completing the feed (no. 8). In four cases the infants experienced weight loss, which indicated the seriousness of the feeding problems. The complexity of feeding problems reported indicated that feeding therapy should be done by a professional with specialist knowledge and experience. Furthermore, collaboration among health professionals is essential, since the feeding problems in the infants were associated with low birth weight and pre-term birth, heart defects, decreased immunity and duodenal atresia (Cousineau \& Lauer, 1995; van Dyke, et al., 1995).

Figure 1 also indicates that all the feeding problems in the infants improved during the 4 to 12 month period. Hunt, et al. (2000) found that infants with Down syndrome develop coordinated oral-motor skills between 7 and 9 months of age. Problems with positioning, a slow swallowing reflex, problems starting sucking and aspiration were not reported in the infants after 6 months (Hunt, et al., $2000)$. The participants also reported that $90 \%$ of their children experienced no feeding problems at the time of data collection, and that only $2(10 \%)$ infants/toddlers still had inadequate feeding skills. These two infants respectively received nasogastric tube feeding and gastrostomy feeding after birth.

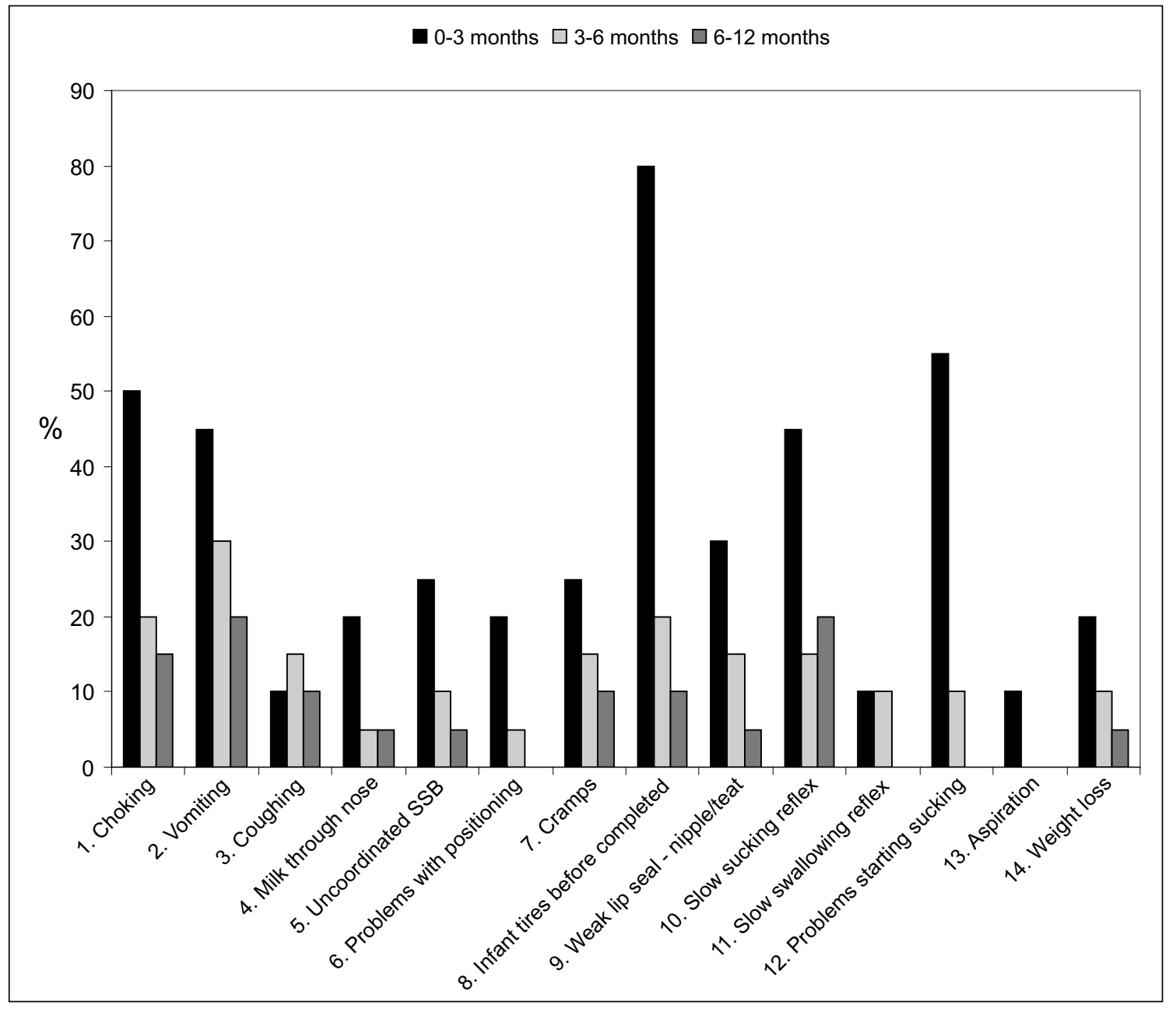

Figure I. Feeding problems experienced by the participants' infants 
Figure 2 indicates the cascading effect of the different feeding problems in the participants' infants. Although the direct cause of each feeding symptom of the infants cannot be determined, the figure is an attempt to systemize the large number and diversity of feeding problems reported by the participants.

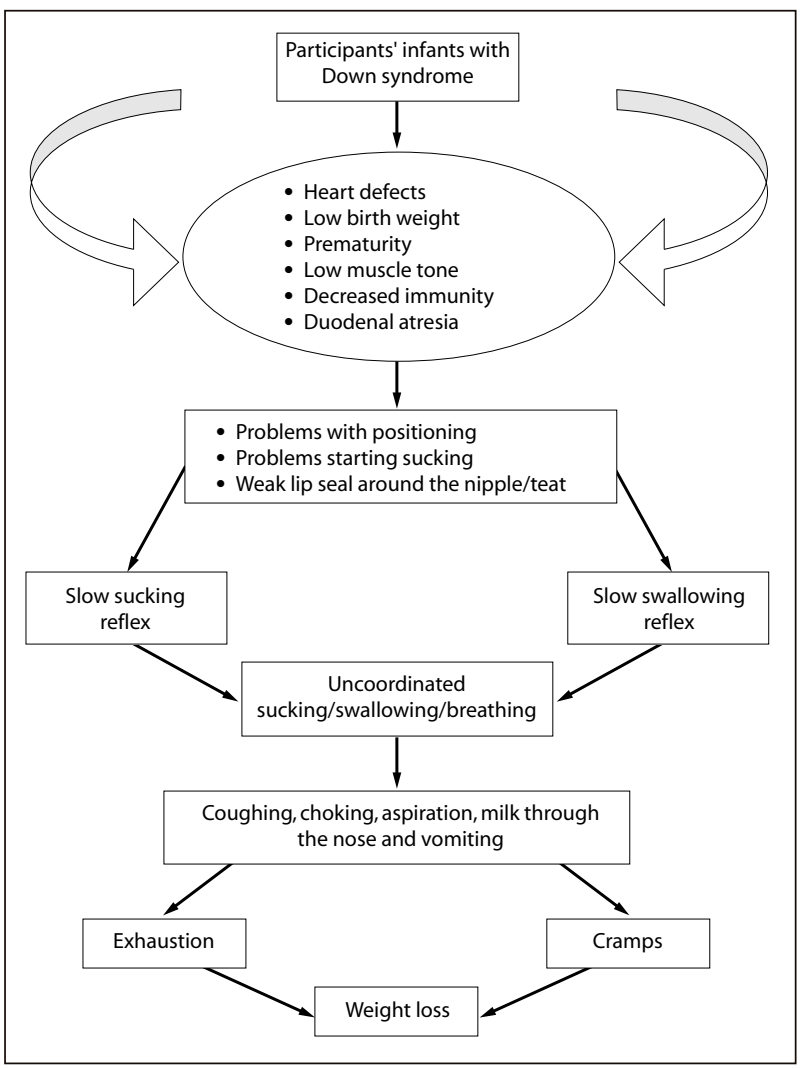

Figure 2. Cascading effect of feeding problems in the participants' infants

\section{Support received during the infants' feeding problems}

A total of $70 \%$ participants reported that they received support from a nurse during the feeding difficulties of their infants. To a lesser degree, support was also provided by speech-language therapists, pediatricians, family members, another mother with an infant with Down syndrome, and an occupational therapist. The participants in general received support from a combination of professionals and non-professionals which is regarded as a positive intervention option by Byrne, Cunningham and Sloper (1988). Mothers with infants with Down syndrome have a unique advantage over professionals since they have firsthand experience of feeding problems, and are able to share concerns, advice and emotional support with another mother in a similar situation. It is regrettable that this intervention option was not available to all the participants in the present study.

The results indicated that the limited feeding intervention provided by speech-language therapists could be related to the limited number of speech-language therapists in early communication intervention in South Africa (Pickering, et al., 1998). Training of mothers with infants with Down syndrome, in order to provide training and support to new parents with infants with Down syndrome and therefore supplement professional services, appear to be a practical solution to the shortage of speech-language therapists in the South African context.

\section{Emotions reported by the participants during the feeding problems of their infants}

The importance of emotional support for mothers while coping with the feeding difficulties of their infants with Down syndrome is emphasized in the results presented in Figure 3

As depicted in Figure 3 the emotions experienced by the participants were reported in three time categories, i.e. emotions that were experienced initially, continuously during the three to four months of their infants' feeding problems and emotions that never presented in the participants. The participants' emotions in the beginning were shock, concern, stress, anxiety, inadequacy, disappointment, anger, frustration and grief. The emotions that most frequently remained throughout the duration of the infants' feeding problems were concern, stress, anxiety, inadequacy, frustration and grief. It appears that the stronger emotional responses, i.e. shock, disappointment and anger in the participants decreased over time. The responses that the participants displayed are typical emotional reactions of parents when they receive the diagnosis of communicative impairment in their children (Roth \& Worthington, 2001) and indicated their need for supportive counseling.

\section{Recommendations made by the participants regarding the feeding difficulties in their infants}

The participants identified support, advice and guidance as the most important contributions of professionals. They felt strongly about handling infants with Down syndrome as normal babies and providing mothers with choices in order to make decisions regarding feeding options. Specific feeding intervention was required for low muscle tone and positioning of the infant and encouragement of breast feeding. The participants therefore provided a rich source of practical suggestions that should be considered in feeding therapy in infants with Down syndrome.

\section{Conclusion}

The complexity of feeding difficulties of infants with Down syndrome should be addressed from birth onwards by an inclusive team with specialist knowledge, skills and sensitivity, and consisting of medical professionals and speechlanguage therapists, as well as non-professionals, i.e. family members and trained mothers who went through the experience of feeding difficulties in their own infants with Down syndrome. 


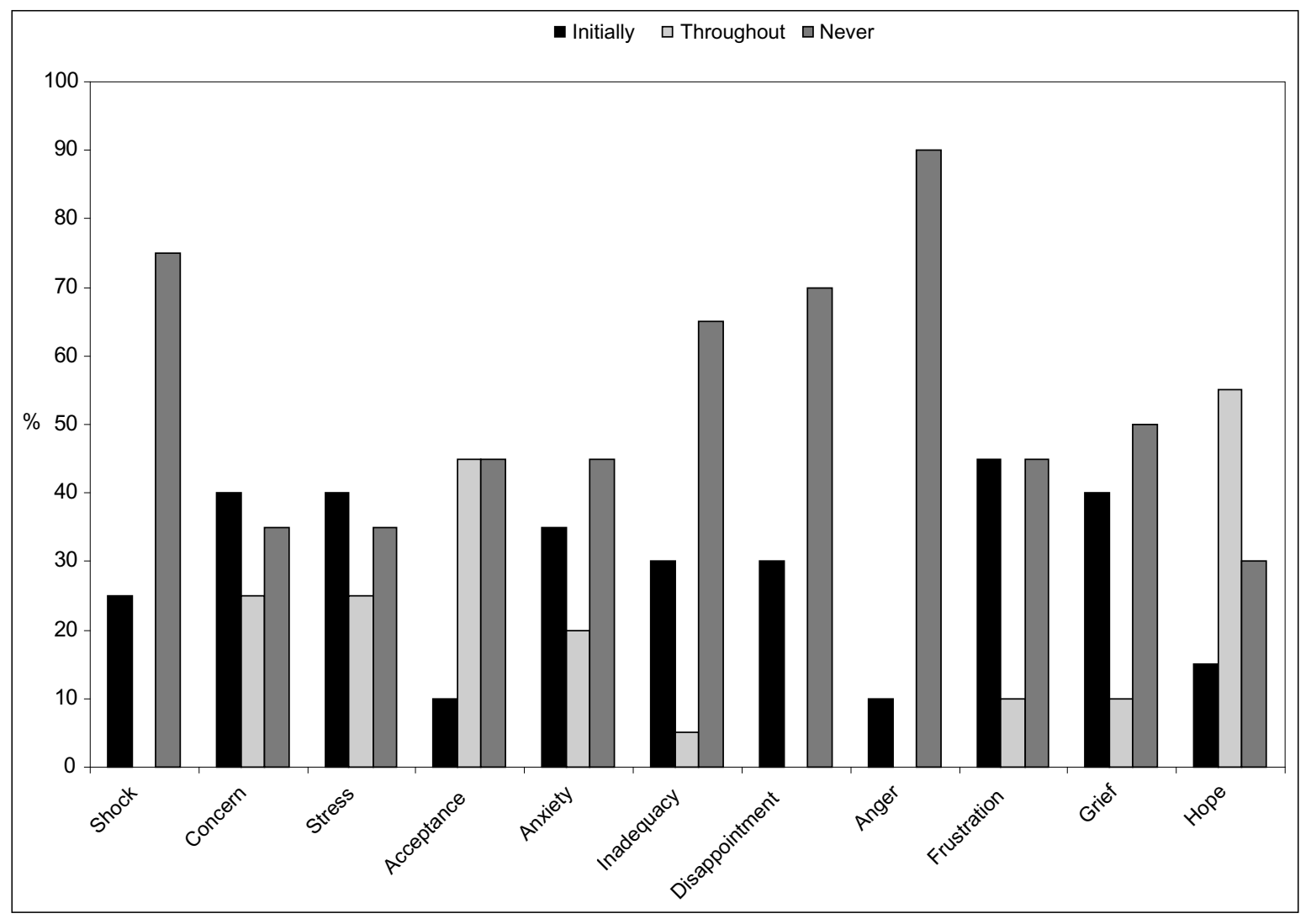

Figure 3. Emotions reported by the participants during the feeding problems of their infants

\section{Correspondence}

Dr Alta Kritzinger • Department of Communication Pathology, University of Pretoria, Pretoria 0002, South Africa - Phone: 27 (I2) 4202949 • Fax: 27 (I2) 4203517 •E-mail: alta.kritzinger@up.ac.za.

\section{References}

Bailey, D.B. (1996). Foreword. In Beckman, P.J. Strategies for Working with Families of Young Children with Disabilities. Baltimore: Paul H. Brookes Publishing Company.

Beck, M. (1999). Expecting Adam. USA: Times Books.

Byrne, E.A., Cunningham, C.C. \& Sloper, P. (1988). Families and their Children with Down's Syndrome: One Feature in Common. USA: Crown Copyright.

Cousineau, A.J. \& Lauer, R.M. (1995). Heart Disease and Children with Down Syndrome. In Van Dyke, D.C., Mattheis, P., Eberly, S.S. \& Williams, J. (Eds.) Medical o Surgical Care for Children with Down Syndrome. A Guide for Parents. Bethesda: Woodbine House.

Cunningham, C. (1982). Down's Syndrome: An Introduction for Parents. London: Souvenir Press.

Gigacz, J. (2001). Breastfeeding a Baby with Down Syndrome. Available: http://www.breastfeeding.asn.au/bfinto/ down.htm] [Accessed: 2002, February 15].

Guralnick, M.J. (1997). The Effectiveness of Early Intervention. Baltimore: Paul H. Brookes Publishing Company.

Hunt, L., Lewis, D., Reisel, S., Waldrup, L. \& Wooster, D.M.A. (2000). Age Norms for Straw-Drinking Abil- ity. Infant-Toddler Intervention. The Transdisciplinary Journal, 10(1), 1-7.

Kumin, L. (1994). Communication Skills in Children with Down Syndrome: A Guide for Parents. Bethesda: Woodbine House.

Kumin, L., Goodman, M. \& Councill, C. (1991). Comprehensive Communication Intervention for Infants and Toddlers with Down Syndrome. Infant-Toddler Intervention. The Transdisciplinary Journal, 1(4), 275-283.

Leedy, P.D. (1997). Practical Research: Planning and Design $\left(6^{\text {th }}\right.$ Ed). Columbus: Merrill Prentice-Hall.

Lubchenco, L.O. (1987). Assessment of Weight and Gestational Age. In Avery, G.B. (Ed.) Neonatology, Pathophysiology and Management of the Newborn. Philadelphia: J.B. Lippencott.

McCurtin, A. (1997). The Manual of Paediatric Feeding Practice. Oxon: Winslow Press.

McWilliams, B.J., Morris, H.L. \& Shelton, R.L. (1990). Cleft Palate Speech. Philadelphia: B.C. Decker.

Pickering, M., McAllister, L., Hagler, P., Whitehill, T.L., Penn, C., Robertson, S.J. \& McCready, V. (1998). External Factors Influencing the Profession in Six Societies. American Journal of Speech-Language Pathology, 7, 5-17.

Pipes, P.L. (1995). Nutrition and Children with Down Syndrome. In Van Dyke, D.C., Mattheis, P., Eberly, S.S. \& Williams, J. Medical \& Surgical Care for Children with Down Syndrome. A Guide for Parents. Bethesda: Woodbine House. 
Pilcher, E.S. (1998). Dental Care for the Patient with Down Syndrome. Available: www.ds-health.com/dental.htm [Accessed: 2002, February, 15].

Rossetti, LM. (2001). Communication Intervention: Birth to Three. $2^{\text {nd }}$ Edition. Australia: Singular Thomson Learning.

Roth, F.P. \& Worthington, C.K. (2001). Treatment Resource Manual for Speech-Language Pathology. $2^{\text {nd }}$ Edition. Australia: Singular Thomson Learning.

Rynders, J.E. \& Horrobin, J.M. (1996). Down Syndrome: Birth to Adulthood. Giving Families an Edge. USA: Love Publishing Company.
Van Dyke, D.C., Mattheis, P., Eberly, S.S. \& Williams, J. (1995). Medical o Surgical Care for Children with Down Syndrome. A Guide for Parents. Bethesda: Woodbine House.

Venter, P.A., Christianson, A.L., Hutamo, C.M., Makhura, M.P. \& Gericke, G.S. (1995). Congenital Anomalies in Rural Black South African Neonates. South African Medical Journal, 85: 15-20.

Wolf, L.S. \& Glass, R.P. (1992). Feeding and Swallowing Disorders in Infancy. Assessment and Management. Tucson: Therapy Skill Builders.

\section{Appendix A: Parental experiences of feeding problems in their infants with Down syndrome}

\section{Questionnaire}

\section{Questionnaire number:}

How to complete this form: Please answer the following questions by indicating your choice with an (x) in the appropriate block, or by giving a description in the spaces provided.

\section{SECTION A}

(1) Baby's name: (optional)

(2) Date of your baby's birth:

(3) Gender: $\mathrm{M} / \mathrm{F}$

(4) Age of mother: years

(5) Number of children in the family:

(6) Position of your baby with Down syndrome in the family ? (e.g. $\left.1^{\text {st }} / 2^{\text {nd }}\right)$

(7) Duration of pregnancy: weeks

(8) Birth weight of your baby: More than 3500g/2500g-3500g / Less than $2500 \mathrm{~g}$

(9) When was the diagnosis of Down syndrome confirmed in your baby? Before birth / 1-2 weeks after birth / If later, when?

(10) Did your baby have any of the following conditions? Heart defect / Low muscle tone / Cleft palate If other, please describe.

(11) After the birth of your baby, did he/she have any of the following conditions, or require any treatments?

\begin{tabular}{|l|l|l|}
\hline CONDITION & PRESENT & DURATION \\
\hline Received oxygen & & \\
\hline Infections & & \\
\hline Cared for on warm table or in incubator & & \\
\hline Ventilator & & \\
\hline Apgar score less than $7 / 10$ & & n.a \\
\hline
\end{tabular}

If other, please describe.

\section{SECTION B:}

(1) How did your baby feed at the following ages?

\begin{tabular}{|l|l|l|l|l|}
\hline & $0-3$ MTHS & $3-6$ MTHS & $6-12$ MTHS & 12-24 MTHS \\
\hline Slow \& inadequate & & & & \\
\hline Moderate, but not as expected & & & & \\
\hline Adequate & & & & \\
\hline Good & & & & \\
\hline
\end{tabular}


(2) When did you become aware that babies with Down syndrome can also have feeding problems? Before birth / After birth

(3) If you breastfed, did you manage? Yes - successfully / No - didn’t try because of feeding problems / No - tried, but was unsuccessful

(4) Indicate the method of feeding that you used, and at what age ranges you used it.

\begin{tabular}{|l|l|l|}
\hline METHOD & FROM & TO \\
\hline Nasogastric tube feeding & & \\
\hline Gastrostomy tube feeding & & \\
\hline Breastfeeding & & \\
\hline Bottle feeding & & \\
\hline Cup feeding & & \\
\hline Spoon-feeding & & \\
\hline
\end{tabular}

Other, please describe.

(5) How frequently did you feed your baby?

\begin{tabular}{|l|l|l|}
\hline TIMES & $\mathrm{X}$ & AGE \\
\hline Less than an hour & & \\
\hline Every hour & & \\
\hline Every 2 hours & & \\
\hline Every 3 hours & & \\
\hline Every 4 hours & & \\
\hline
\end{tabular}

(6) Approximately how long did each feeding last during the first week after the birth of your baby? 5-10 minutes / 10-20 minutes / Longer than $1 / 2$ hour / 50 minutes / 60 minutes

\section{SECTION C:}

(1) Did your baby experience any of the following problems? (Please mark all applicable)

\begin{tabular}{|l|l|l|l|}
\hline CONDITION & $0-3$ MTHS & $3-6$ MTHS & 6-12 MTHS \\
\hline Choking & & & \\
\hline Vomiting & & & \\
\hline Coughing & & & \\
\hline Milk came through nose & & & \\
\hline Poor coordination of suck/swallow/breathing & & & \\
\hline Cramps & & & \\
\hline Baby tired before feeding is completed & & & \\
\hline Poor lip seal & & & \\
\hline Delayed suck reflex & & & \\
\hline Delayed swallow reflex & & & \\
\hline Difficulty to latch on to breast/teat & & & \\
\hline Aspiration & & & \\
\hline Weight loss & & & \\
\hline
\end{tabular}

Other, please describe.

(2) Did any of the following people help you with your baby's feeding? If yes, who?

Pediatrician / Gynaecologist / Nurse / Speech-language therapist / Physiotherapist / Occupational therapist / Other parent with an infant with Down syndrome / Family member / Other, please name. 
(3) Did any of the professional people give you the opportunity to decide on the best feeding methods for your baby? Y/N If yes, who?

(4) How long did your baby's feeding problems last? A few months / 1 Year / 2 Years / Longer than 2 years

(5) How does your baby feed currently?

Slowly \& inadequately / Moderate, but not as expected / Adequately / Good

\section{SECTION D:}

(1) Which feelings did you experience regarding your infant's feeding during the first 3-4 months?

\begin{tabular}{|l|l|l|l|}
\hline & AT FIRST & CONTINUOUSLY & NEVER \\
\hline Shock & & & \\
\hline Distress & & & \\
\hline Tension & & & \\
\hline Acceptance & & & \\
\hline Anxiety & & & \\
\hline Felt inadequate & & & \\
\hline Disappointment & & & \\
\hline Anger & & & \\
\hline Frustration & & & \\
\hline Grief & & & \\
\hline Hope & & & \\
\hline
\end{tabular}

Other? Please name.

(2) As a result of the feeding problems, which of the following emotions did you experience if you had to leave your baby at a caregiver?

Didn't want to leave my baby at a caregiver / Wanted to, but couldn't, because of the feeding problems / Left my baby at a caregiver because of commitments at work, but wasn't at ease / Left my baby at a caregiver because of commitments at work, and was at ease.

(3) Based on your experience regarding feeding, do you have any suggestions that professionals could use for handling the feeding problems of new babies with Down syndrome in the future? Please describe.

(4) Which suggestions can you make to future parents with a baby with Down syndrome, who has feeding problems?

Thank you for taking the time to complete this form. 